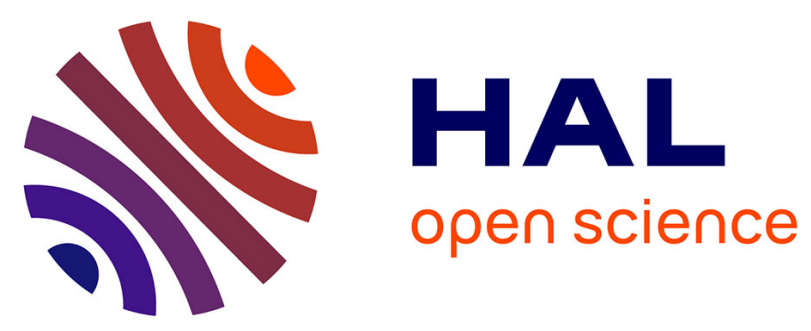

\title{
Statistical analysis of VLF radio emissions triggered by power line harmonic radiation and observed by the low-altitude satellite DEMETER
}

Michel Parrot, František Nĕmec, Ondřej Santolík

\section{- To cite this version:}

Michel Parrot, František Nĕmec, Ondřej Santolík. Statistical analysis of VLF radio emissions triggered by power line harmonic radiation and observed by the low-altitude satellite DEMETER. Journal of Geophysical Research Space Physics, 2014, 119, pp.5744-5754. 10.1002/2014JA020139 . insu01174151

HAL Id: insu-01174151

https://hal-insu.archives-ouvertes.fr/insu-01174151

Submitted on 8 Jul 2015

HAL is a multi-disciplinary open access archive for the deposit and dissemination of scientific research documents, whether they are published or not. The documents may come from teaching and research institutions in France or abroad, or from public or private research centers.
L'archive ouverte pluridisciplinaire HAL, est destinée au dépôt et à la diffusion de documents scientifiques de niveau recherche, publiés ou non, émanant des établissements d'enseignement et de recherche français ou étrangers, des laboratoires publics ou privés. 


\section{Journal of Geophysical Research: Space Physics}

\section{BRIEF REPORT}

10.1002/2014JA020139

Key Points:

- PLHR triggers new emissions

- The events are observed at

high latitudes

- Triggered emissions are due to waveparticle interaction at the equator

Correspondence to:

M. Parrot,

mparrot@cnrs-orleans.fr

\section{Citation:}

Parrot, M., F. Němec, and O. Santolík (2014), Statistical analysis of VLF radio emissions triggered by power line harmonic radiation and observed by the low-altitude satellite DEMETER, J. Geophys. Res. Space Physics, 119, 5744-5754, doi:10.1002/2014JA020139.

Received 29 APR 2014 Accepted 9 JUN 2014 Accepted article online 13 JUN 2014 Published online 8 JUL 2014

\section{Statistical analysis of VLF radio emissions triggered by power line harmonic radiation and observed by the low-altitude satellite DEMETER}

\author{
Michel Parrot ${ }^{1}$, František Němec ${ }^{2}$, and Ondřej Santolík ${ }^{2,3}$ \\ ${ }^{1}$ LPC2E/CNRS, Orléans, France, ${ }^{2}$ Faculty of Mathematics and Physics, Charles University in Prague, Prague, Czech Republic, \\ ${ }^{3}$ Institute of Atmospheric Physics AS CR, Prague, Czech Republic
}

\section{Introduction}

Power Line Harmonic Radiation (PLHR) consists of ELF and VLF waves at the harmonic frequencies of 50 or $60 \mathrm{~Hz}$ radiated by electric power systems on the ground. Frequency-time spectrograms of these events typically consist of several horizontal lines with mutual separation of $50 / 100$ or $60 / 120 \mathrm{~Hz}$. Evidence of PLHR propagation in the magnetosphere was first obtained from the ground-based observations [Helliwell et al., 1975]. Before the DEMETER microsatellite was launched, direct observations by satellites were still rather rare and described only in a few papers [Bell et al., 1982; Koons et al., 1978; Tomizawa and Yoshino, 1985; Rodger et al., 1995]. A systematic study of PLHR observations by DEMETER was performed by Němec et al. [2006, 2007b, 2008, 2010] (see also references to other observations therein). They showed that the frequency spacing of the lines corresponds well to the power system frequency in possible generation regions. More recently these events have been also observed onboard CHIBIS-M by Pronenko et al. [2014].

Němec et al. [2010] have also shown that PLHR events are too weak and the individual lines forming them are too narrow to significantly increase the total wave intensity above industrialized regions. However, there are some indications that PLHR is able to trigger new emissions. Such emissions were theoretically analyzed by Nunn et al. [1999]. Using a simulation code, they were able to reproduce the shape of an event recorded by a ground-based instrumentation in Finland. Many more Scandinavian events recorded with a magnetic loop antenna have been presented by Manninen [2005]. The aim of this paper is to report all observations of emissions triggered by PLHR and observed by DEMETER. Concerning the data analysis, we have used the same approach as for the natural waves recently studied by Parrot et al. [2014]. The wave experiment onboard DEMETER is briefly introduced in section 2. Some characteristic events are presented in section 3. Section 4 describes some of the statistical properties of the observed events, whereas section 5 is devoted to their possible relation with Magnetospheric Line Radiation (MLR). The obtained results are discussed in section 6 and summarized in section 7 .

\section{The DEMETER Satellite}

DEMETER was a LEO (Low Earth Orbiting) microsatellite launched on 29 June 2004. Its orbit was polar and circular with an altitude of $\sim 710 \mathrm{~km}$ which was subsequently lowered to $650 \mathrm{~km}$ at the end of 2005 till the end of the mission in December 2010 [Cussac et al., 2006]. The orbit was nearly Sun-synchronous with a local time at $\sim 22: 30$ LT during the nighttime and at 10:30 LT during daytime. The payload was continuously 


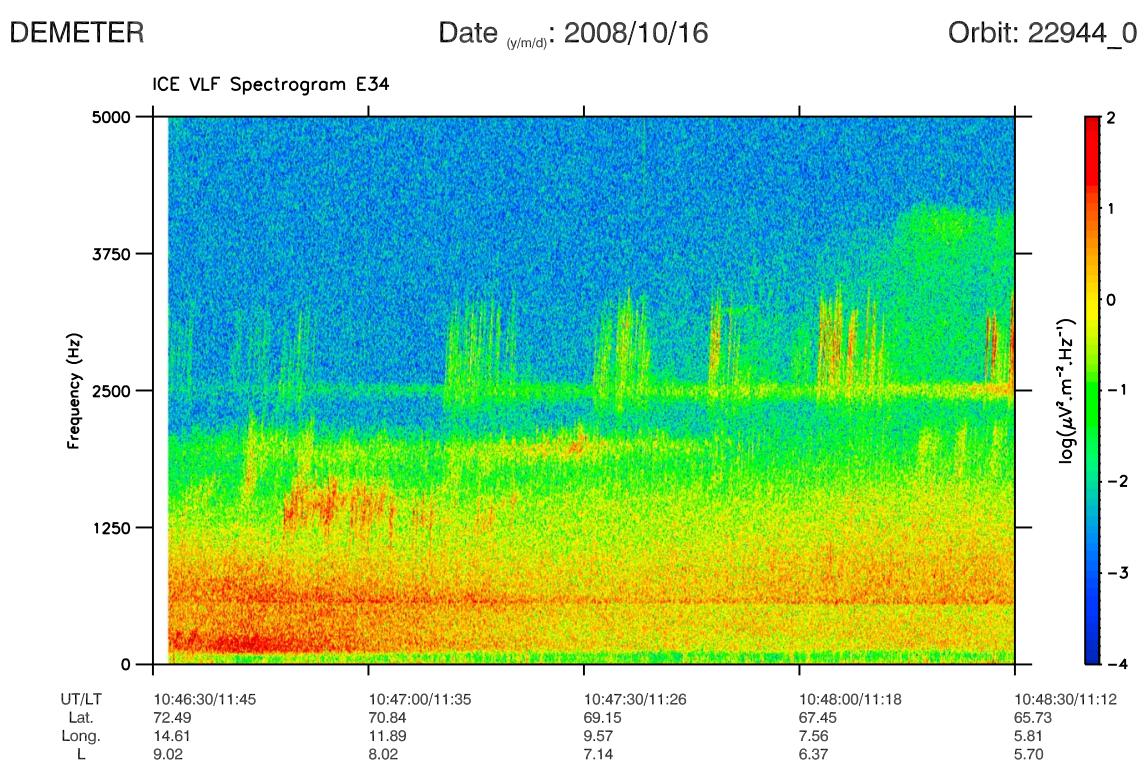

Figure 1. Spectrogram of an electric field component recorded on 16 October 2008 between 10:46:30 and 10:48:30 UT. The spectrogram is from 0 up to $5 \mathrm{kHz}$, and its intensity is color coded according to the scale on the right. Its frequency resolution is $9.7 \mathrm{~Hz}$, and its time resolution is $0.1 \mathrm{~s}$. The parameters displayed below are the time in UT, the local time (LT), the geographic latitude and longitude, and the Mcllwain parameter $L$.

operated at invariant latitudes below $65^{\circ}$, but dedicated operations were also programmed at higher latitudes when the satellite was traveling over ground-based facilities such as European Incoherent Scatter (EISCAT) or High Frequency Active Auroral Research Program (HAARP). Data reported in this paper were acquired by the instrument champ électrique (ICE) which measures electric components of plasma waves in the frequency range from $\mathrm{DC}$ to $3.25 \mathrm{MHz}$. The very low frequency (VLF) range of ICE extends from $70 \mathrm{~Hz}$ to $20 \mathrm{kHz}$. There are two scientific modes, survey and burst; the latter being mainly activated when the satellite is above active seismic regions or for specific purposes. In both modes, power spectra of one electric component were calculated on board with a time resolution of $2.048 \mathrm{~s}$ and a frequency resolution of $19.53 \mathrm{~Hz}$. In the burst mode, waveforms of one electric component with a sampling frequency of $40 \mathrm{kHz}$ were downloaded, which allows spectra with a better time and frequency resolution than in survey mode. During the burst mode periods, one can perform a wave propagation analysis using the six components of the wavefield up to $1.25 \mathrm{kHz}$. For this reason, a software named PRASSADCO used in the past for other missions has been revised to analyze the DEMETER data [Santolík et al., 2006].

A detailed description of ICE can be found in Berthelier et al. [2006]. All events shown in this paper have been recorded during the burst mode of the experiment.

\section{Examples of Events}

Figure 1 represents a spectrogram of an electric field component recorded on 16 October 2008 during 2 min over Scandinavia. The frequency is from 0 up to $5 \mathrm{kHz}$. The spectral line which is observed around $2.5 \mathrm{kHz}$ with a bandwidth of the order of $100 \mathrm{~Hz}$ can be attributed to PLHR. This is also the starting frequency of triggered elements which can be seen both below and above this line. Other structured elements can be seen at lower frequencies, but PLHR lines are not detected. The cutoff at $\sim 600 \mathrm{~Hz}$ is close to the proton gyrofrequency and is usually observed on a low-altitude satellite [see, for example, Santolík and Parrot, 1999]. This cutoff is present on all spectrograms shown in the following figures. A second example of triggered emissions is presented in the middle of Figure 2 which displays hooks. At the beginning of the plot, they are clearly supported by a parent line around $2250 \mathrm{~Hz}$. After 04:46:00 UT, this line disappears but the hooks remain until the end of the plot. At lower frequencies (around $1250 \mathrm{~Hz}$ ), other hooks can also be observed but without parent line. These hooks are very similar to those detected on ground by Helliwell [1965],

Nunn et al. [1999], and Manninen [2005]. Data in Figure 2 are recorded on 12 January 2010 when the satellite is over the Indian Ocean at a location which is magnetically conjugated to Russia. Other hooks can be seen in 
DEMETER Date ${ }_{(y / m(n):)}: 2010 / 01 / 12 \quad$ Orbit: 29596_0

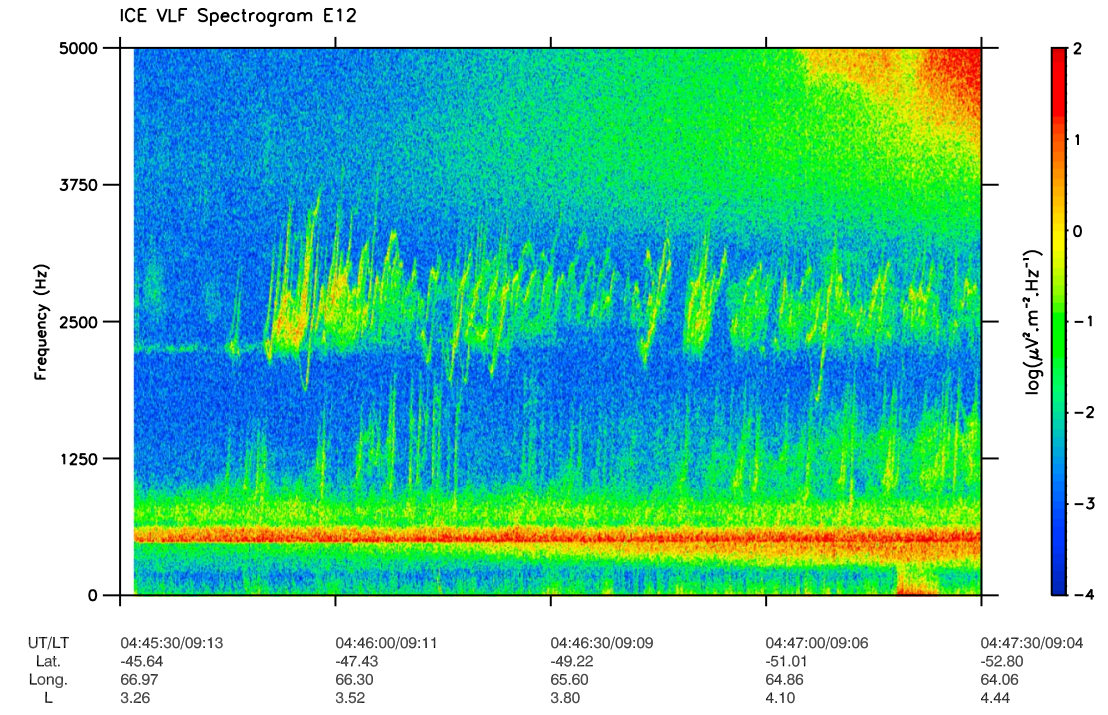

Figure 2. Similar to Figure 1 but with data recorded on 12 January 2010 between 04:45:30 and 04:47:30 UT.

Figure 3 but without a parent line. These data are recorded on 26 January 2008 close to Alaska. The last example of hooks is displayed in Figure 4. It concerns data recorded on 17 February 2008 along the same halforbit over two magnetically conjugated regions. Figure 4 (top) shows hooks around $2.5 \mathrm{kHz}$ which are recorded in the Northern Hemisphere (close to Alaska) whereas Figure 4 (bottom) shows hooks at similar frequencies in the Southern Hemisphere.

Other examples of triggered emissions associated to PLHR can be seen in Parrot and Němec [2009, Figure 5].

\section{The Statistical Analysis}

Figure 5 shows locations of the 65 events which have been registered in the burst mode during the DEMETER operation. This number of observed events is not representative of the real number of cases which can be expected with a LEO satellite. This is due to the fact that DEMETER did not record data at high latitudes and

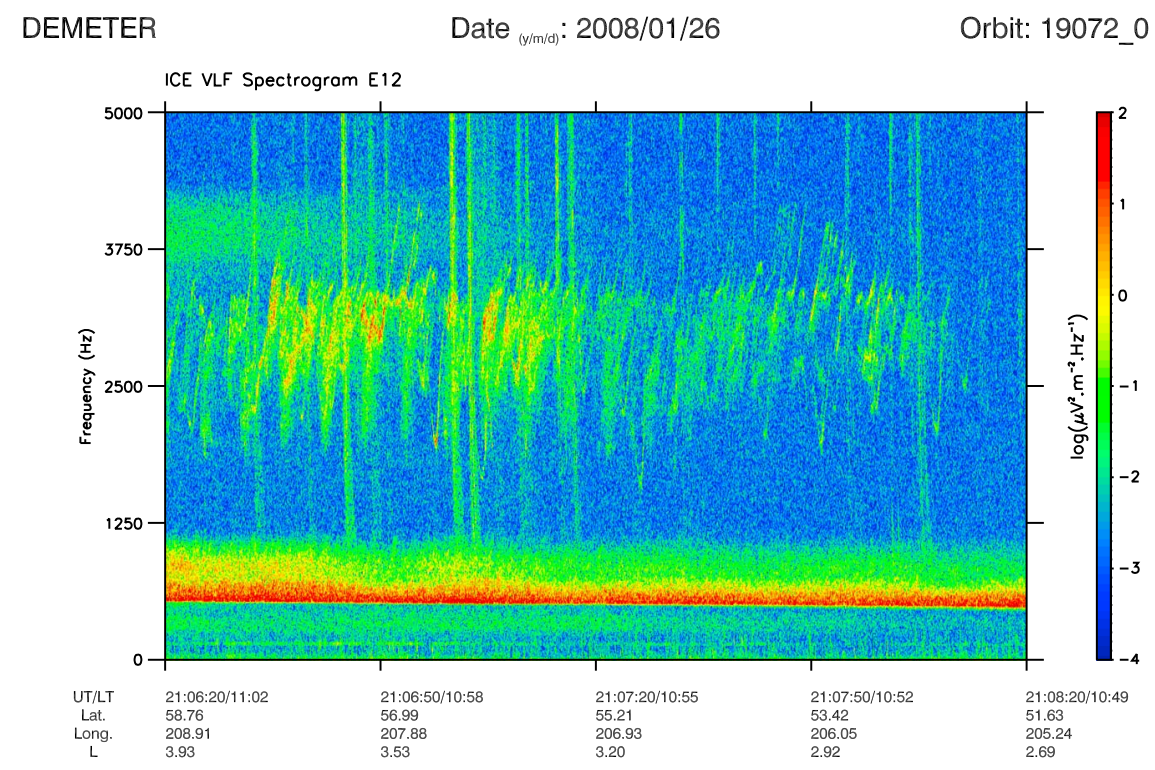

Figure 3. Similar to Figure 2 but with data recorded on 26 January 2008 between 21:06:20 and 21:08:20 UT. 


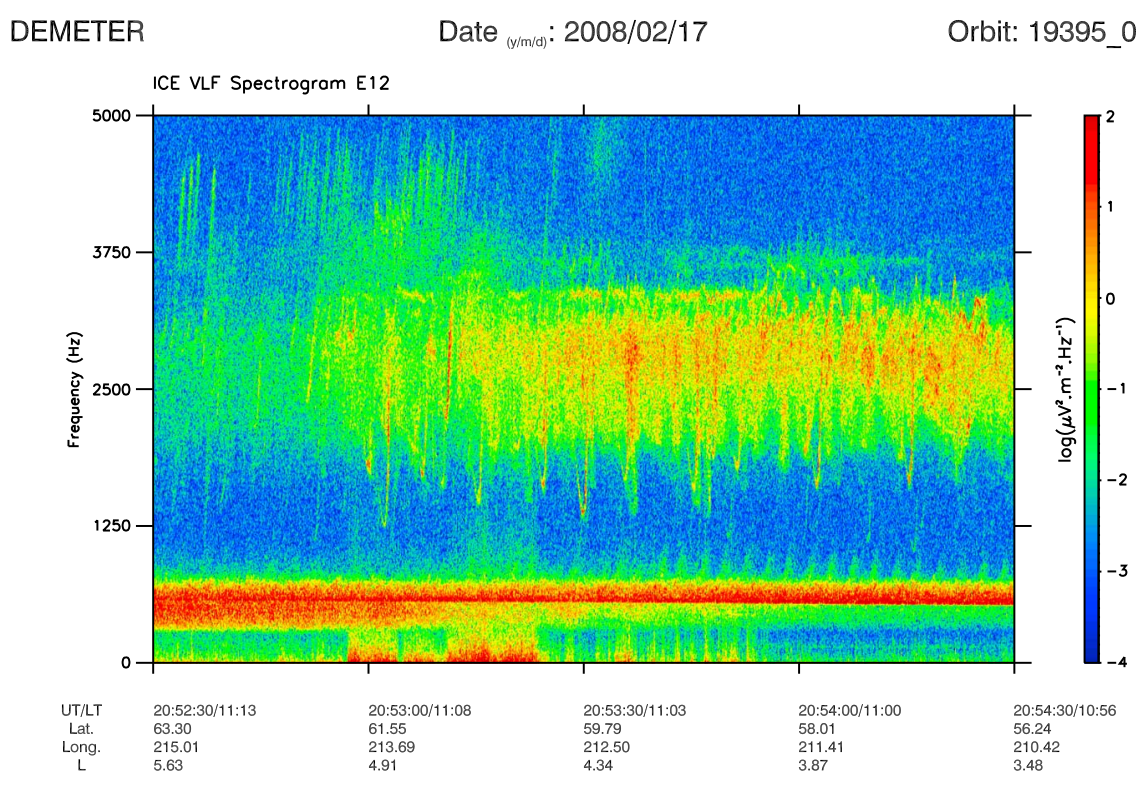

DEMETER Date (UIm(m) $_{20}: 2008 / 02 / 17 \quad$ Orbit: $19395 \_0$

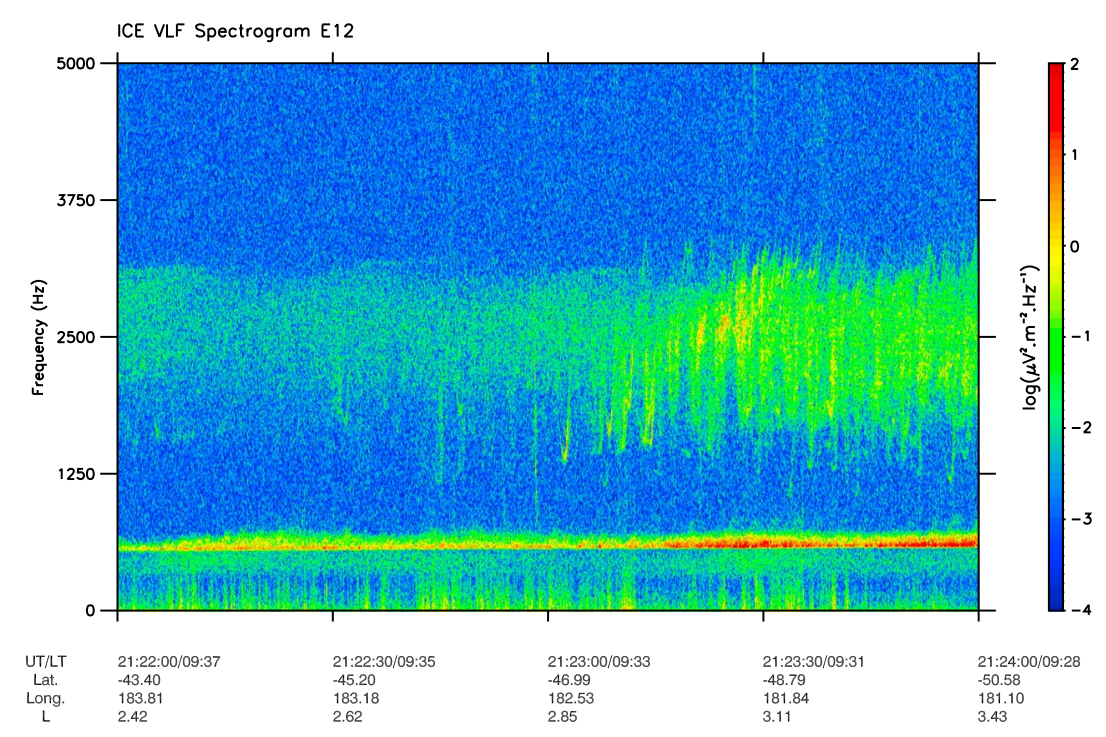

Figure 4. (top) Similar to Figure 3 but with data recorded on 17 February 2008 between 20:52:30 and 20:54:30 UT. (bottom) Similar to Figure 4 (top) but with data recorded later on the same half-orbit in the opposite hemisphere between 21:22:00 and 21:24:00 UT.

that only the data registered during the burst mode have been scrutinized (the burst mode coverage is color coded in Figure 5). During the survey mode, the frequency resolution is not enough for a proper detection of this type of waves. Nonetheless, it can be seen in Figure 5 that there is no clear longitudinal dependence and that these events have been equally recorded at high latitudes in the north and in the south $(3<L<6)$. It appears that many events were recorded during the extension of the DEMETER burst mode for experiments with HAARP, HAARP conjugate, and EISCAT [see, for example, Piddyachiy, 2012]. In fact, many events are detected when DEMETER is close to its normal limit of invariant latitude (see Figure 5).

These events are observed between 1 and $4 \mathrm{kHz}$ which is the usual frequency band of the PLHR [Nĕmec et al., 2007a] and mainly during daytime (85\%). Their average intensity is of the order of $10 \mu \mathrm{V}^{2} \mathrm{~m}^{-2} \mathrm{~Hz}^{-1}$. 


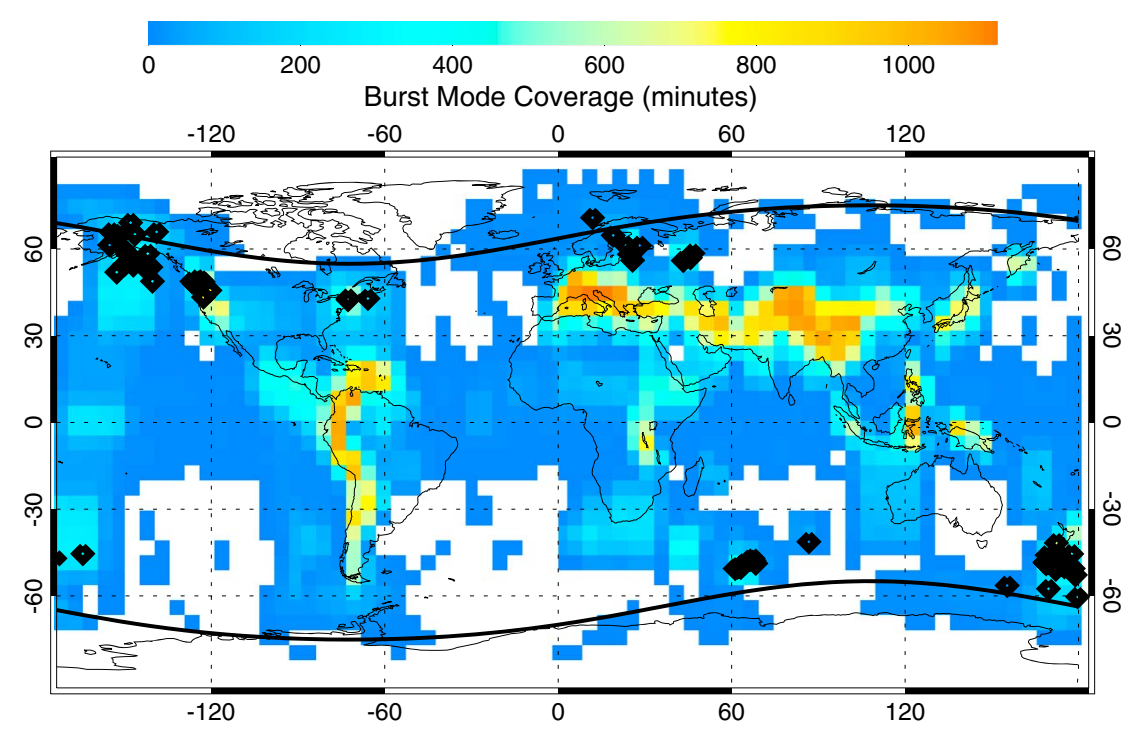

Figure 5. Geographical occurrence of the 65 events observed during the lifetime of the mission (black diamonds). The two black lines correspond to the invariant latitude of $65^{\circ}(L \sim 6)$. The map also shows the burst mode coverage according to the color scale at the top.

It is important to check if the events occur during normal geomagnetic conditions or not. Therefore, we have used a superposed epoch method to reveal the correlation between the timing of these waves and the $A E$ index amplitude. The time resolution used for the comparison was set to $1 \mathrm{~h}$. The results are shown in Figure 6 . The thick line shows the mean value of the $A E$ index whereas its standard deviation is indicated by thin lines. It can be seen that there is a very small increase of the $A E$ index a few days before the events, on average by about $50 \mathrm{nT}$ as compared to normal values. This means that the events are preferentially observed in the recovery phase of magnetic substorms (see section 6).

\section{On the Possible Relation With MLR}

As opposed to the constant frequency of PLHR waves (1-4 kHz), Magnetospheric Line Radiation (MLR) has lines drifting in frequencies with a larger bandwidth $(1-8 \mathrm{kHz})$. Although they have been extensively studied [Bell et al., 1982; Rodger et al., 1995, 1999, 2000a, 2000b; Parrot et al., 2007; Nemec et al., 2007a, 2009a, 2009b,

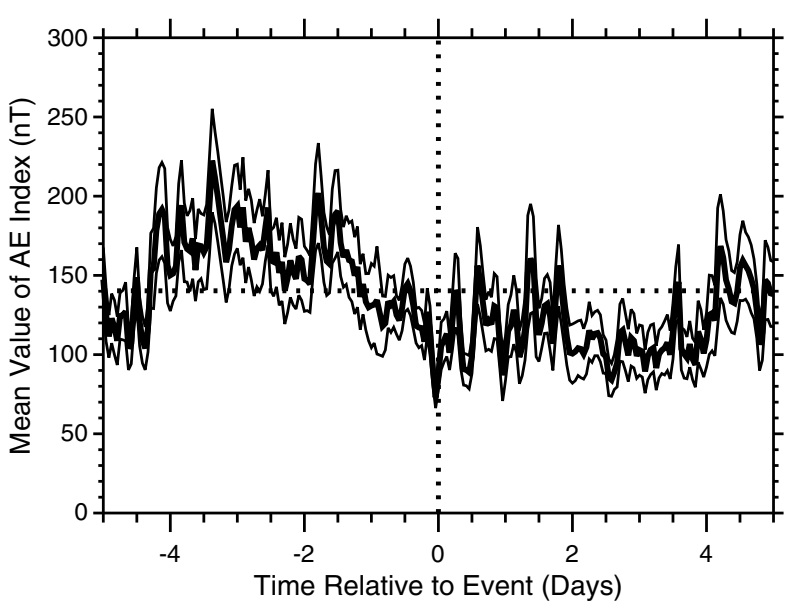

Figure 6. Results of the superposed epoch analysis of the $A E$ index. Its mean value (bold) as a function of the time relative to the occurrence of the 65 events and the standard deviation of the mean value (thin). The vertical dotted line shows zero time difference, and the horizontal dotted line shows the average $A E$ value over the duration of the DEMETER mission.
$2012 a, 2012 b]$, there is a controversy about the origin of these lines which are observed in space or on the ground because many of them are separated by neither 50 nor $60 \mathrm{~Hz}$. Another difference between these two emissions is underlined in Figure 7 which presents simultaneous observations of MLR and triggered emissions without parent lines. Figure 7 (top) shows an electric field spectrogram recorded on 28 November 2006 between 21:54:59 and 22:28:29 UT along a complete half-orbit. One can see MLR around $2.5 \mathrm{kHz}$ in both hemispheres at high latitudes (above Alaska and its conjugate region). Around 22:25:30 UT, the two white vertical lines indicate the presence of a burst mode and Figure 7 (bottom) shows the corresponding detailed spectrogram between 0 and $5 \mathrm{kHz}$. Triggered elements similar to those shown in Figure 1 


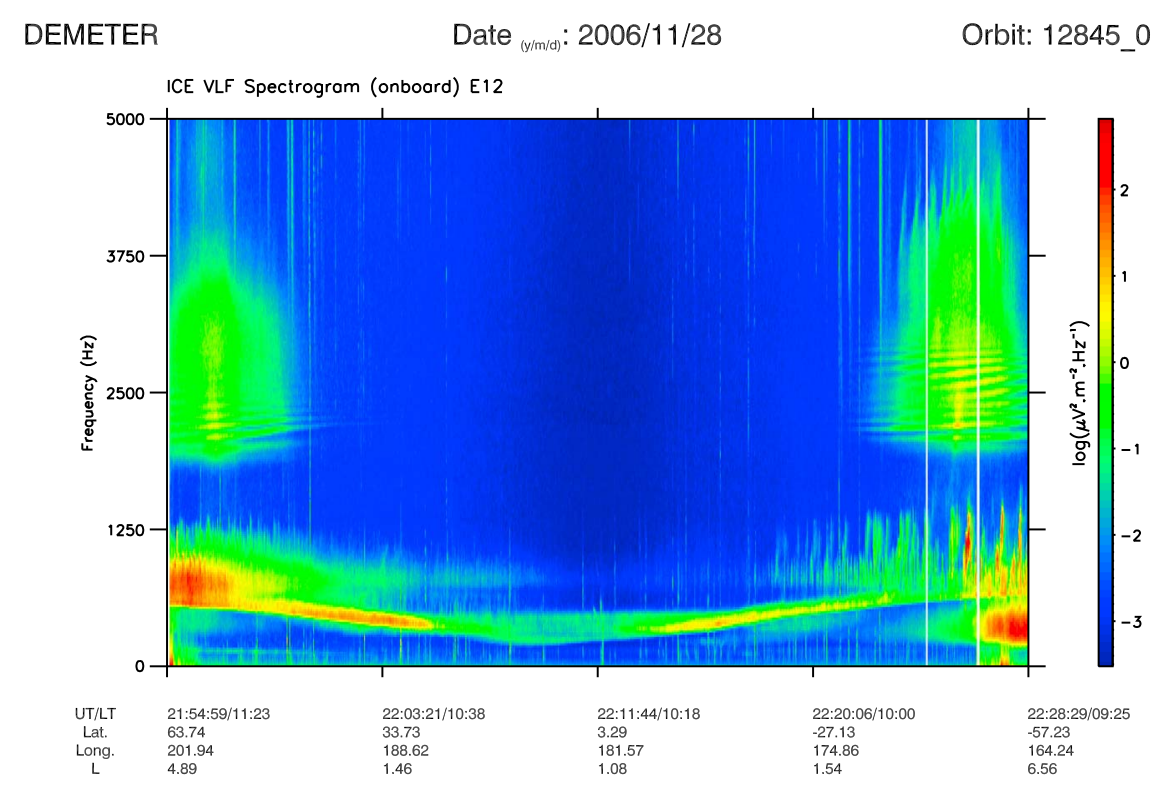

DEMETER Date ${ }_{(y / m / \alpha)}: 2006 / 11 / 28 \quad$ Orbit: $12845 \_0$

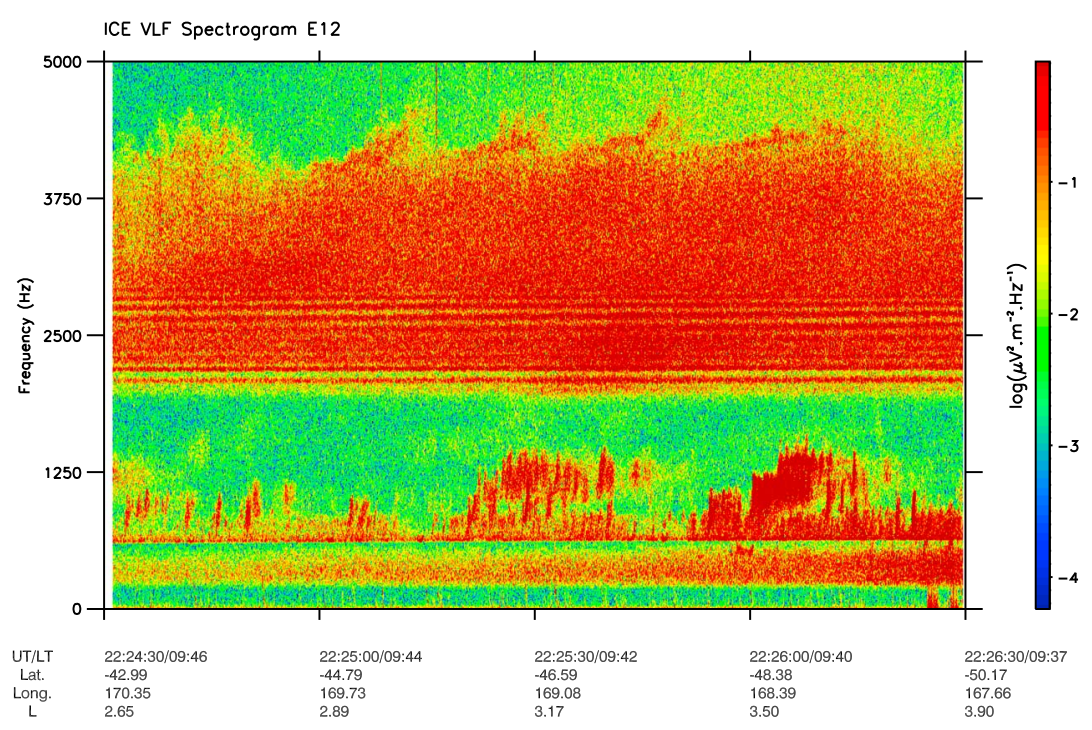

Figure 7. (top) Similar to Figure 1 but with data recorded on 28 November 2006 between 21:54:59 and 22:28:28 UT and in the frequency range $0-20 \mathrm{kHz}$. The location of the burst mode is indicated by the two vertical white lines. (bottom) Detailed spectrogram corresponding to the burst mode time interval with a frequency range between $0 \mathrm{and} 5 \mathrm{kHz}$.

are observed around $1 \mathrm{kHz}$ but without parent lines. The set of MLR lines is observed around $2.5 \mathrm{kHz}$, and it can be seen that they do not trigger emissions. This is a general behavior. Sometimes they are only modulated as quasiperiodic (QP) emissions (see, for example, Helliwell [1965] or Parrot and Němec [2009, Figure 3]). It must be also noticed that QP emissions are observed above $4 \mathrm{kHz}$ in Figure 7 (bottom) which is an indication of magnetically perturbed conditions.

It is possible to determine the propagation characteristics of waves observed at frequencies lower than $1.25 \mathrm{kHz}$ from the burst mode data, when the six components of the electromagnetic field are available (see section 2). Figure 8 shows the wave propagation analysis of the burst mode event in Figure 7 (bottom). The first two panels represent frequency-time spectrograms of the wave magnetic and electric fields. The third panel displays the parameter $F$ which is the planarity of polarization $F$ of the magnetic field fluctuations obtained using the Singular Value Decomposition (SVD) method [Santolik et al., 2003]. This parameter is close to unity for a polarization state 


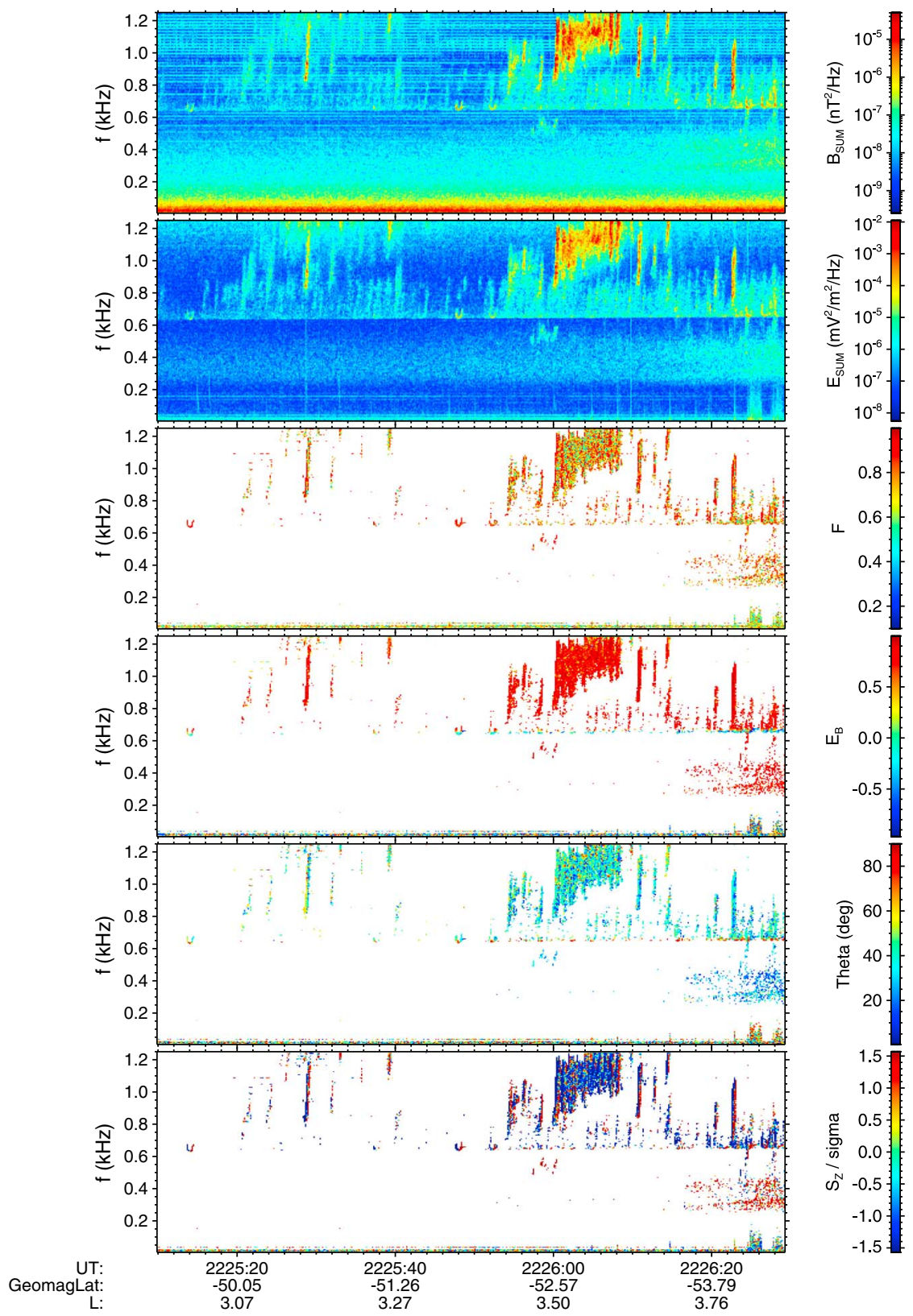

Figure 8. Wave propagation analysis of the event shown in Figure 7. (from top to bottom) The magnetic field spectrogram, the electric field spectrogram, the planarity of polarization of the wave magnetic field, the ellipticity of magnetic field, the polar angle $\theta$, and the Poynting vector component along the terrestrial magnetic field normalized by the standard deviation (see text for explanation). All parameters are color coded according to the scales on the right. The frequency range is up to $1250 \mathrm{~Hz}$. The parameters displayed on the abscissa are the time in UT, the geomagnetic latitude, and the Mcllwain parameter $L$.

which corresponds to a single plane wave, it decreases to zero for randomly polarized waves. The ellipticity $E_{B}$ (the fourth panel) has been obtained as the ratio of the two largest axes of the polarization ellipsoid using the SVD method. The sign of this parameter reflects the sense of polarization: negative values mean the left-handed sense and positive values mean the right-handed sense. The SVD method is also used to calculate the direction of the wave vector (the fifth panel) defined by the angle $\theta$ from the Earth's magnetic field. The sixth panel gives the Poynting vector component along the terrestrial magnetic field normalized by its standard deviation resulting from the statistical errors of the spectral analysis [Santolik et al., 2001]. For waves propagating from the equator we expect to obtain positive values at positive latitudes and negative values at negative latitudes. 


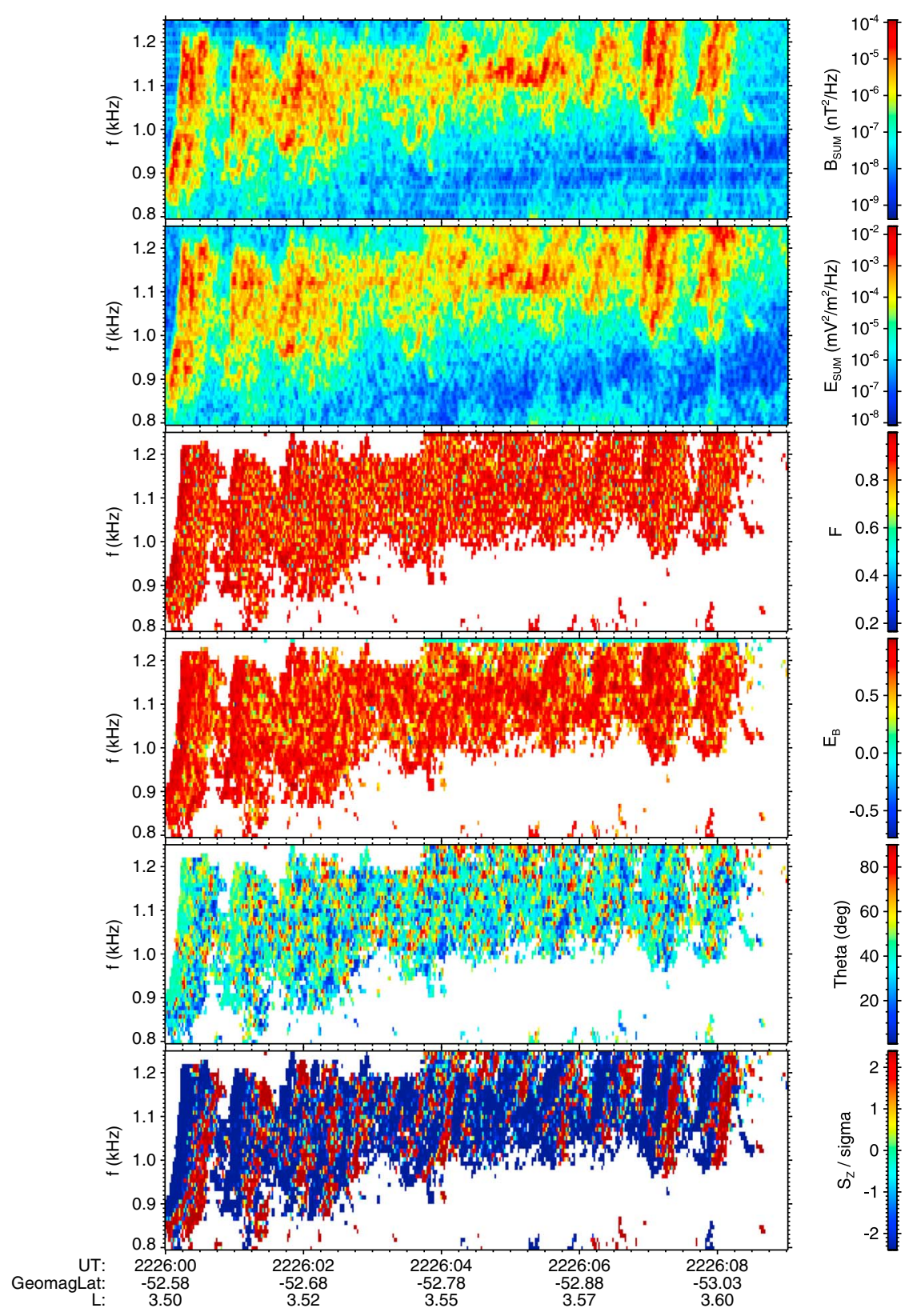

Figure 9. Zoom of Figure 8 for the wave elements observed between 22:26:00 and 22:26:09 UT in the frequency range $800-1250 \mathrm{~Hz}$.

The empty areas in the panels correspond to frequency-time intervals with magnetic power spectral densities below $10^{-7} \mathrm{nT}^{2} \mathrm{~Hz}^{-1}$ or electric power spectral densities below $10^{-6} \mathrm{mV}^{2} \mathrm{~m}^{-2} \mathrm{~Hz}^{-1}$. These areas are empty because the analysis is not meaningful for low power waves.

The results of this multidimensional analysis of plasma wave measurements as a function of the universal time (UT) and frequency indicate that the waves are quasi field-aligned (low $\theta$ values) and right-handed circularly polarized $\left(E_{B}\right.$ is close to +1$)$. Concerning the propagation, a zoom of Figure 8 has been performed in Figure 9. The meaning of individual panels is the same as in Figure 8. It concerns the elements which are observed between 22:26:00 and 22:26:09 UT in the frequency range 800-1250 Hz. This fine-scale analysis indicates in the sixth panel that the elements are first propagating in the opposite direction of the Earth's magnetic field (blue part). As the event takes place in the Southern Hemisphere, it means that the waves are propagating away from the geomagnetic equator. But just 
after this first part of each element, the waves are propagating in the direction of the Earth's magnetic field (red part) which means that they undergo a reflection below the satellite.

\section{Discussions}

These events recorded onboard DEMETER are the counterpart of previous ground-based observations [see, for example, Nunn et al., 1999, Figure 1]. The two main differences are that the parent lines are not always observed on the satellite events and that there is a frequency broadening of these parent lines. All possible PLHR lines are not observed at the altitude of the satellite due to their attenuation during the propagation through the ionosphere. According to Ando et al. [2002] and Jing et al. [2014], the attenuation is scarce as function of the altitude but more important as function of the distance from the source. The broadening of the parent line can be attributed to possible interactions with the ionospheric plasma at high latitudes as it is the case for signals coming from VLF ground-based transmitters and crossing the ionosphere [see, for example, Bell et al., 1981; Titova et al., 1984]. Concerning this latter point one must say that this study is not in contradiction with the work by Němec et al. [2010]. In their statistical analysis they identified the PLHR events with an automatic algorithm and found typical PLHR which consisted of several very thin lines (see their Figure 1). This explains why principally no PLHR-triggered emissions were found when they looked for that.

Results shown in Figure 6 mean that the events are predominantly observed after geomagnetic substorms when energetic charged particles are present in the magnetosphere. Using a simulation code, Nunn et al. [1999] have shown that the triggered emissions could be attributed to nonlinear wave-particle interactions. In addition, Figure 5 indicates that a combination of two other factors is needed in order to observe these triggered emissions: (i) location above industrialized regions or conjugated (to have PLHR) and (ii) high-latitude regions. This second condition is necessary in order that the PLHR encounters most of particles at the equator which is the main region suitable for wave-particle interactions through cyclotron resonance mechanism (see, for example, Liemohn [1967] or more recent advances in Trakhtengerts and Rycroft [2008]). Cyclotron resonance interactions are strongest near the equatorial plane because the local cyclotron frequency and the resonant parallel electron energy are minimum along a given magnetic field line.

The fact that hooks shown in Figure 2 are observed together with a parent line above the Indian Ocean (an uninhabited area) is a further evidence of propagation of PLHR through the magnetosphere and across the equatorial region. For this event, PLHR are supposed to be emitted from Russia.

Figure 4 indicates that hooks are observed quasi-simultaneously in both hemispheres. For this event, PLHR are supposed to be emitted most probably from Alaska in the Northern Hemisphere, but it could also be emitted from New Zealand in the Southern Hemisphere. The triggered emissions are emitted in the equatorial region and can propagate down to the ionosphere. Although observations in both hemispheres could not be simultaneous (there is a delay of approximately half an hour) and are not always in the burst mode in both hemispheres, we have found that among the 65 events, there are nine events where triggered emissions have a counterpart in the opposite hemisphere.

The propagation analysis done for the event shown in Figures 7 and 8 confirms that these elements are propagating away from the geomagnetic equator. This is consistent with the proposed localization of the source region of the triggered elements in the equatorial region which is the most favorable region for wave-particle interactions.

\section{Conclusions}

In this paper, triggered emissions associated to PLHR and observed by the low-altitude satellite DEMETER have been investigated. To summarize observations and discussions, one can say the following:

1. These emissions appear either as a series of short rising tones or as a series of hooks. The starting frequency of these elements is often associated to a parent line with a frequency close to a multiple of 50 or $60 \mathrm{~Hz}$. When the parent line is not seen, it is assumed that it is too weak to be observed but that it is present as the starting frequency of the elements remains close to a multiple of 50 or $60 \mathrm{~Hz}$. 
2. The emissions are observed during moderate magnetic activity at high latitudes above industrialized regions (or magnetically conjugate parts of these regions).

3. MLR do not appear to trigger such elements and mainly look as a frequency modulation of preexisting hiss (Figure 7 (top)).

Finally, it is noteworthy that it is possible to confound these series of short rising tones with chorus elements. In the past, Luette et al. [1977] showed that chorus emissions tend to occur more frequently along longitudes that contain industrial centers which are located at high latitudes. They suggested that PLHR can stimulate chorus emissions through cyclotron resonance with trapped energetic electrons. This will be the subject of a forthcoming paper with DEMETER data.

\section{Acknowledgments}

This work was supported by the Centre National d'Etudes Spatiales. It is based on observations with the electric field instrument ICE aboard DEMETER. The data for this paper are available at http://cdpp2. cnes.fr/cdpp/login.do. The work of F.N. was supported by GACR grant P209/12/ P658. O.S. was supported by GACR grant 205/10/2279 and MSMT grant LH12231. The authors thank J. J. Berthelier the PI of ICE for the use of the data.

Alan Rodger thanks Michael Rycroft and another reviewer for their assistance in evaluating this paper.

\section{References}

Ando, Y., M. Hayakawa, and O. A. Molchanov (2002), Theoretical analysis on the penetration of power line harmonic radiation into the ionosphere, Radio Sci., 37(6), 1093, doi:10.1029/2001RS002486.

Bell, T. F., U. S. Inan, and R. A. Helliwell (1981), Nonducted coherent VLF waves and associated triggered emissions observed on the ISEE-1 satellite, J. Geophys. Res., 86(A6), 4649-4670, doi:10.1029/JA086iA06p04649.

Bell, T. F., J. P. Luette, and U. S. Inan (1982), ISEE 1 observations of VLF line radiation in the Earth's magnetosphere, J. Geophys. Res., 87(A5), 3530-3536, doi:10.1029/JA087iA05p03530.

Berthelier, J. J., et al. (2006), ICE, the electric field experiment on DEMETER, Planet. Space Sci., 54, 456-471, doi:10.1016/j.pss.2005.10.016.

Cussac, T., M.-A. Clair, P. Ultré-Guerard, F. Buisson, G. Lassalle-Balier, M. Ledu, C. Elisabelar, X. Passot, and N. Rey (2006), The DEMETER microsatellite and ground segment, Planet. Space Sci., 54, 413-427, doi:10.1016/j.pss.2005.10.013.

Helliwell, R. A. (1965), Whistlers and Related lonospheric Phenomena, Stanford Univ. Press, Stanford, Calif.

Helliwell, R. A., J. P. Katsufrakis, T. F. Bell, and R. Raghuram (1975), VLF line radiation in the Earth's magnetosphere and its association with power system radiation, J. Geophys. Res., 80(31), 4249-4258, doi:10.1029/JA080i031p04249.

Jing, W., F. Jing-Jing, and Z. Chong (2014), Propagation characteristics of power line harmonic radiation in the ionosphere, Chin. Phys. B, 23(3), 034102, 6.

Koons, H. C., M. H. Dazey, and B. C. Edgar (1978), Satellite observation of discrete VLF line radiation within transmitter-induced amplification bands, J. Geophys. Res., 83(A8), 3887-3889, doi:10.1029/JA083iA08p03887.

Liemohn, H. B. (1967), Cyclotron-resonance amplification of VLF and ULF whistlers, J. Geophys. Res., 72(1), 39-55, doi:10.1029/JZ072i001 p00039.

Luette, J. P., C. G. Park, and R. A. Helliwell (1977), Longitudinal variations of very-low-frequency chorus activity in the magnetosphere: Evidence of excitation by electrical power transmission lines, Geophys. Res. Lett., 4(7), 275-278, doi:10.1029/GL004i007p00275.

Manninen, J. (2005), Some Aspects of ELF-VLF Emissions in Geophysical Research, vol. 98, Oulu Univ. Press, Oulu, Finland.

Němec, F., O. Santolík, M. Parrot, and J. J. Berthelier (2006), Power line harmonic radiation (PLHR) observed by the DEMETER spacecraft, J. Geophys. Res., 111, A04308, doi:10.1029/2005JA011480.

Němec, F., O. Santolik, M. Parrot, and J. J. Berthelier (2007a), Comparison of magnetospheric line radiation and power line harmonic radiation A systematic survey using the DEMETER spacecraft, J. Geophys. Res., 112, A04301, doi:10.1029/2006JA012134.

Němec, F., O. Santolík, M. Parrot, and J. J. Berthelier (2007b), Power line harmonic radiation: A systematic study using DEMETER spacecraft, Adv. Space Res., 40(3), 398-403, doi:10.1016/j.asr.2007.01.074.

Němec, F., O. Santolík, M. Parrot, and J. Bortnik (2008), Power line harmonic radiation observed by satellite: Properties and propagation through the ionosphere, J. Geophys. Res., 113, A08317, doi:10.1029/2008JA013184.

Němec, F., M. Parrot, O. Santolík, C. J. Rodger, M. J. Rycroft, M. Hayosh, D. Shklyar, and A. Demekhov (2009a), Survey of magnetospheric line radiation events observed by the DEMETER spacecraft, J. Geophys. Res., 114, A05203, doi:10.1029/2008JA014016.

Němec, F., T. Raita, M. Parrot, O. Santolík, and T. Turunen (2009b), Conjugate observations on board a satellite and on the ground of a remarkable MLR-like event, Geophys. Res. Lett., 36, L22103, doi:10.1029/2009GL040974.

Němec, F., M. Parrot, and O. Santolík (2010), Influence of power line harmonic radiation on the VLF wave activity in the upper ionosphere: Is it capable to trigger new emissions?, J. Geophys. Res., 115, A11301, doi:10.1029/2010JA015718.

Němec, F., M. Parrot, and O. Santolík (2012a), Detailed properties of magnetospheric line radiation events observed by the DEMETER spacecraft, J. Geophys. Res., 117, A05210, doi:10.1029/2012JA017517.

Němec, F., O. Santolík, M. Parrot, and J. S. Pickett (2012b), Magnetospheric line radiation event observed simultaneously on board Cluster 1 , Cluster 2 and DEMETER spacecraft, Geophys. Res. Lett., 39, L18103, doi:10.1029/2012GL053132.

Nunn, D., J. Manninen, T. Turunen, V. Trakhtengerts, and N. Erokhin (1999), On the nonlinear triggering of VLF emissions by power line harmonic radiation, Ann. Geophys., 17, 79-94.

Parrot, M., and F. Němec (2009), MLR events and associated triggered emissions observed by DEMETER, Adv. Space Res., 44, 979-986, doi:10.1016/j.asr.2009.07.001.

Parrot, M., J. Manninen, O. Santolík, F. Němec, T. Turunen, T. Raita, and E. Macúšová (2007), Simultaneous observation on board a satellite and on the ground of large-scale magnetospheric line radiation, Geophys. Res. Lett., 34, L19102, doi:10.1029/2007GL030630.

Parrot, M., F. Němec, and O. Santolík (2014), Analysis of fine ELF wave structures observed poleward from the ionospheric trough by the lowaltitude satellite DEMETER, J. Geophys. Res. Space Physics, 119, 2052-2060, doi:10.1002/2013JA019557.

Piddyachiy, D. (2012), Propagation of ELF waves generated by an HF ionospheric heater in the Earth's plasma environment, PhD thesis, Stanford Univ., Stanford, Calif.

Pronenko, V., V. Korepanov, and D. Dudkin (2014), Power lines harmonic radiation in circumterrestrial space, EGU General Assembly, 16, abstract EGU2014-2065. [Available at http://meetingorganizer.copernicus.org/EGU2014/EGU2014-2065.pdf.]

Rodger, C. J., N. R. Thomson, and R. L. Dowden (1995), VLF line radiation observed by satellite, J. Geophys. Res., 100(A4), 5681-5689, doi:10.1029/94JA02865.

Rodger, C. J., M. A. Clilverd, K. H. Yearby, and A. J. Smith (1999), Magnetospheric line radiation observations at Halley, Antarctica, J. Geophys. Res., 104(A8), 17,441-17,447, doi:10.1029/1999JA900153.

Rodger, C. J., M. A. Clilverd, K. H. Yearby, and A. J. Smith (2000a), Temporal properties of magnetospheric line radiation, J. Geophys. Res., 105(A1), 329-336, doi:10.1029/1999JA900420. 
Rodger, C. J., M. A. Clilverd, K. H. Yearby, and A. J. Smith (2000b), Is magnetospheric line radiation man made?, J. Geophys. Res., 105(A7), 15,981-15,990, doi:10.1029/1999JA000413.

Santolík, O., and M. Parrot (1999), Case studies on wave propagation and polarization of ELF emissions observed by FREJA around local proton gyro-frequency, J. Geophys. Res., 104(A2), 2459-2475, doi:10.1029/1998JA900045.

Santolík, O., F. Lefeuvre, M. Parrot, and J. L. Rauch (2001), Complete wave-vector directions of electromagnetic emissions: Application to INTERBALL-2 measurements in the nightside auroral zone, J. Geophys. Res., 106(A7), 13,191-13,201, doi:10.1029/2000JA000275.

Santolík, O., M. Parrot, and F. Lefeuvre (2003), Singular value decomposition methods for wave propagation analysis, Radio Sci., 38(1), 1010, doi:10.1029/2000RS002523.

Santolík, O., F. Nĕmec, M. Parrot, D. Lagoutte, and L. Madrias (2006), Analysis methods for multi-component wave measurements on board the DEMETER spacecraft, Planet. Space Sci., 54, 512-527, doi:10.1016/j.pss.2005.10.020.

Titova, E. E., V. I. Di, V. E. Yurov, O. M. Raspopov, V. Y. Trakhtengertz, F. Jiricek, and P. Triska (1984), Interaction between VLF waves and the turbulent ionosphere, Geophys. Res. Lett., 11(4), 323-326, doi:10.1029/GL011i004p00323.

Tomizawa, I., and T. Yoshino (1985), Power line radiation observed by the satellite Ohzora, J. Geomagn. Geoelectr., 37, $309-327$.

Trakhtengerts, V. Y., and M. J. Rycroft (2008), Whistler and Alfvén Mode Cyclotron Masers in Space, Cambridge Univ. Press, Cambridge, U. K. 